\title{
Psychiatric history and subthreshold symptoms as predictors of the occurrence of depressive or anxiety disorder within 2 years
}

Julie Karsten, Catharina A. Hartman, Johannes H. Smit, Frans G. Zitman, Aartjan T. F. Beekman, Pim Cuijpers, A. J. Willem van der Does, Johan Ormel, Willem A. Nolen and Brenda W. J. H. Penninx

\section{Background}

Past episodes of depressive or anxiety disorders and subthreshold symptoms have both been reported to predict the occurrence of depressive or anxiety disorders. It is unclear to what extent the two factors interact or predict these disorders independently.

\section{Aims}

To examine the extent to which history, subthreshold symptoms and their combination predict the occurrence of depressive (major depressive disorder, dysthymia) or anxiety disorders (social phobia, panic disorder, agoraphobia, generalised anxiety disorder) over a 2-year period.

\section{Method}

This was a prospective cohort study with 1167 participants: the Netherlands Study of Depression and Anxiety. Anxiety and depressive disorders were determined with the Composite International Diagnostic Interview, subthreshold symptoms were determined with the Inventory of Depressive Symptomatology-Self Report and the Beck Anxiety Inventory.

\section{Results}

Occurrence of depressive disorder was best predicted by a combination of a history of depression and subthreshold symptoms, followed by either one alone. Occurrence of anxiety disorder was best predicted by both a combination of a history of anxiety disorder and subthreshold symptoms and a combination of a history of depression and subthreshold symptoms, followed by any subthreshold symptoms or a history of any disorder alone.

\section{Conclusions}

A history and subthreshold symptoms independently predicted the subsequent occurrence of depressive or anxiety disorder. Together these two characteristics provide reasonable discriminative value. Whereas anxiety predicted the occurrence of an anxiety disorder only, depression predicted the occurrence of both depressive and anxiety disorders.

\section{Declaration of interest}

W.A.N. has received speaking fees from Astra Zeneca, Eli Lilly, Pfizer, Servier, Wyeth; unrestricted research funding from Astra Zeneca, Eli Lilly, GlaxoSmithKline, Wyeth; and served on advisory boards for Astra Zeneca, Cyberonics, Eli Lilly, GlaxoSmithKline, Pfizer, Servier.
Depressive and anxiety disorders are among the most common, persistent ${ }^{2}$ and disabling ${ }^{1,3,4}$ psychiatric disorders. In addition to research on ways to expand and improve the effectiveness of mental healthcare for those with depressive or anxiety disorders, recent efforts have been aimed at preventive interventions. ${ }^{5,6}$ In order to increase the effectiveness of preventive psychosocial or pharmacological strategies it is necessary to know which individuals are at highest risk. Individuals with a history of episodes of depressive disorder are at a greater risk of suffering subsequent episodes, ${ }^{7,8}$ as are those with depressive symptoms that do not meet the criteria for major depressive disorder, i.e. subthreshold depression. ${ }^{9,10}$ The same holds true for anxiety disorders, for which past episodes ${ }^{2,10}$ and subthreshold anxiety $^{11,12}$ also predict occurrence. However, history of disorder and subthreshold symptoms are seldom evaluated in a single study, although this is important in order to unravel their unique contribution to the prediction of depression or anxiety. Moreover, their simultaneous evaluation can reveal whether people with both a history of disorder and subthreshold symptoms are at increased risk compared with those with either alone. Information on the relative weight of history and subthreshold symptoms in predicting depression or anxiety may form a resource for targeting efficiently those who might benefit most from preventive measures. The present study aims to determine the predictive value of both factors, separately and in combination. It uses data from a large cohort study on depression and anxiety disorders in The Netherlands. We first report the 2-year occurrence rates for common depressive (major depressive disorder and dysthymia) and anxiety disorders (social phobia, panic disorder, agoraphobia and generalised anxiety disorder). Subsequently, we examine the extent to which a history of a disorder, subthreshold symptoms and a combination of the two determine the risk for the occurrence of depressive and anxiety disorders over a 2-year period.

\section{Method}

\section{Procedure}

Data were derived from an 8-year longitudinal cohort study, the Netherlands Study of Depression and Anxiety (NESDA). ${ }^{13}$ The study examines the aetiology and predictors of the long-term course of depressive and anxiety disorders. Its rationale and methods have been described elsewhere. ${ }^{13}$ Assessments consisted of $4 \mathrm{~h}$ face-to-face interviews with additional data collection by means of written questionnaires. The present study reports on data from the baseline and 2-year follow-up assessments. The general exclusion criteria of NESDA were the presence of a clinical diagnosis of major psychiatric disorders other than depressive or anxiety disorder (e.g. psychosis, bipolar disorder, severe addictive disorder) or lack of fluency in the Dutch language. In the present study focusing on the occurrence of depressive or anxiety disorder, participants who had experienced depressive or anxiety disorder in the 6 months before baseline were excluded from analyses. 


\section{Participants}

To represent various settings and stages of psychopathology, NESDA recruited respondents from three different settings: the general population $(n=564)$, primary care $(n=1610)$ and mental health organisations $(n=807)$, resulting in a total of 2981 respondents. Participants from the general population were selected from previous studies for their increased risk of depressive or anxiety disorder (participants with either a history of disorder or with a parent with a mood or anxiety disorder). ${ }^{13}$ Participants from primary care consisted of individuals who had screened positive as well as a random subset of screen-negative individuals in a two-step screening approach involving the written extended Kessler Psychological Distress Scale $(\mathrm{EK}-10)^{14}$ and a telephone screen using the Composite International Diagnostic InterviewShort Form (CIDI-SF) ${ }^{15}$ The EK-10 included the 10-item Kessler Psychological Distress Scale (K10), ${ }^{16}$ extended with five anxiety questions, previously shown to yield higher sensitivity for depressive and anxiety disorders. ${ }^{14}$ A screen-positive score on the $\mathrm{EK}-10$ was defined as a $\mathrm{K}-10$ score of $\geqslant 20$ or a positive score on any of the added anxiety questions. A screen-positive CIDI-SF was defined as a positive score on the depression sections (major depressive disorder or dysthymia) or the anxiety sections (social phobia, panic disorder, agoraphobia or generalised anxiety disorder). Mental healthcare patients were recruited when they were newly enrolled at participating mental health organisation locations.

Of the 2981 respondents in NESDA, 1701 (57.1\%) had had a depressive and/or an anxiety disorder within the 6 months before baseline and were excluded in the present study. Of the remaining 1280 respondents, $1177(92.0 \%)$ participated in the 2-year follow-up interview, of which 1167 (99.2\%) completed the required questionnaires. Non-response was significantly associated with two of the covariates used in the present study, i.e. higher number of somatic illnesses $(P<0.001)$ and fewer years of education $(P=0.001)$, but not with age and gender. In short, the sample analysed in this study comprised 1167 respondents from the general population $(n=380)$ and primary care $(n=787)$ and constitutes a mixture of individuals in remission, individuals at risk of developing a first episode and individuals in neither of these categories.

\section{Measures}

\section{Demographic and somatic health factors}

Age, gender, years of education and number of somatic conditions were included as basic sociodemographic and clinical determinants, as they are commonly related to depression and anxiety. ${ }^{17}$ Age, gender and years of education were assessed in the baseline interview. As a general indicator of somatic health, we assessed the presence (yes/no) of 16 somatic conditions commonly assessed in Dutch epidemiological studies (e.g. Netherlands Mental Health Survey and Incidence Study (NEMESIS) ${ }^{18}$ and the Longitudinal Aging Study Amsterdam (LASA) ${ }^{19}$ ) during the baseline interview: lung disease, heart conditions, diabetes, stroke, arthritis, cancer, hypertension, ulcers, intestinal disorders, liver disease, epilepsy, chronic fatigue syndrome, allergies, thyroid disease, head injuries and other injuries.

\section{Mental disorders}

History (yes/no) and occurrence (yes/no) of depressive (major depressive disorder, dysthymia) and anxiety disorders (social phobia, panic disorder, agoraphobia, generalised anxiety disorder) were assessed using the depression and anxiety sections of the Composite International Diagnostic Interview (CIDI, lifetime version 2.1). ${ }^{20}$ History of a disorder was defined as the occurrence of the disorder at any time during the individual's lifespan (but not within the 6 months before baseline; these individuals were excluded from the analyses). Occurrence of a disorder was defined as the onset of the disorder anytime between the baseline and the 2-year follow-up measurement. The overall median time between baseline and 2-year follow-up was 735 days, with an interquartile range of 724 to 756 days.

\section{Subthreshold mental disorders}

Subthreshold depression at baseline was assessed with the Inventory of Depressive Symptomatology-Self Report (IDS-SR 30 ). ${ }^{21}$ The IDS-SR 30 is a 30 -item self-report questionnaire assessing the severity of depressive symptoms. The items are rated on a four-point Likert scale ranging from zero to three. The total score is obtained by summing 28 of the 30 items, with a total score ranging from 0 to 84 , which can be categorised according to severity: 0-13, normal; 14-25, mild depression; 26-38 moderate depression; 39-48, severe depression and 49-84, very severe depression. ${ }^{22}$ High concurrent validity has been shown between the IDS-SR 30 and the depression factor of the Symptom Check List-90 items, Revised (SCL-90-R) ${ }^{23}$ and the Hamilton Rating Scale for Depression (HRSD). ${ }^{24}$ Furthermore, high internal consistency was found for the IDS-SR $\mathrm{S}_{30}$ overall, ${ }^{23,25}$ which was confirmed in our study (Cronbach's $\alpha=0.84$ ) without participants with full-syndromal depressive disorder. Subthreshold depression was defined as a score of at least 14 on the IDS-SR $\mathrm{R}_{30}$. This was based on our previous study about the clinical relevance of subthreshold depressive disorder. We found that participants without depressive disorder but with a score of at least 14 (i.e. at least mild depression) on the IDS-SR $\mathrm{SR}_{30}$ experienced substantially more functional impairment than participants scoring within the normal range (0-13). Receiver operating characteristic (ROC) analyses indicated that this cut-off identified $60 \%$ of the most dysfunctional participants without major depressive disorder or dysthymia, with a sensitivity of 0.79 and a specificity of $0.84 .{ }^{26}$

Subthreshold anxiety at baseline and 2-year follow-up was assessed using the Beck Anxiety Inventory (BAI). ${ }^{27}$ The BAI is a 21-item self-report questionnaire developed to assess anxiety, with a focus on somatic symptoms. The items are rated on a four-point Likert scale ranging from zero (not at all) to three (severely: I could barely stand it). The total score ranges from 0 to 63 and is commonly categorised as follows: $0-9$, normal or no anxiety; 10-18, mild to moderate anxiety; 19-29, moderate to severe anxiety; and 30-63, severe anxiety. ${ }^{22}$ As an indication of concurrent validity, moderate to high correlation was found between the BAI and the SCL-90-R anxiety factor ${ }^{28}$ and a moderate correlation between the BAI and the Hamilton Rating Scale for Anxiety (HRSA). ${ }^{29}$ Furthermore, high internal consistency was found in several studies ${ }^{28,30}$ and confirmed in our study (Cronbach's $\alpha=0.86$ ) without participants with fullsyndromal anxiety disorders. Subthreshold anxiety was defined as a score of at least 11 on the BAI. In a recent study, we found that participants without anxiety disorders but with a BAI score of at least 11 (i.e. at least mild anxiety) experienced more functional impairment than participants with a BAI score within the normal anxiety range (0-9). The ROC analyses indicated that a cut-off score of 11 on the BAI identified the $36 \%$ of most dysfunctional participants without social phobia, panic disorder, agoraphobia or generalised anxiety disorder. ${ }^{31}$

\section{Statistical analyses}

First, we calculated the occurrence rates of depressive disorders, i.e. major depressive disorder or dysthymia, since the baseline interview. We differentiated between respondents with and 
without subthreshold depression at baseline, and respondents with and without a history of depressive disorder. Similarly, we calculated the occurrence rates of anxiety disorders, i.e. social phobia, panic disorder, agoraphobia or generalised anxiety disorder, since the baseline interview, while differentiating between respondents with and without subthreshold anxiety at baseline on the one hand, and respondents with and without a history of anxiety on the other.

Second, we used univariate and multiple logistic regression analyses to assess the extent to which subthreshold symptoms, history and combinations of both predicted the occurrence of depressive disorder and anxiety disorder over 2 years. To this end, we combined these two variables into a single variable divided into four categories (using three dummy variables): (a) without a history of disorder, without subthreshold symptoms, (b) with a history of disorder, without subthreshold symptoms, (c) without a history of disorder, with subthreshold symptoms, (d) with a history of disorder, with subthreshold symptoms. Gender, age, years of education and number of somatic illnesses were also included in these analyses as basic sociodemographic and clinical predictors.

The value of the full model as a predictor of occurrence was estimated using the concordance statistic ( $c$-statistic, i.e. the area under the ROC curve). Concordance statistics between 0.7 and 0.8 are generally considered as acceptable, those between 0.8 and 0.9 as excellent. $^{32}$

\section{Results}

\section{Sample characteristics}

Sample characteristics at baseline are provided in Table 1.

\section{Occurrence of depressive and anxiety disorders}

The rates of depressive disorders (major depressive disorder or dysthymia) are shown in Table 2 and Fig. 1. Of the 369 respondents with baseline subthreshold depression, 27.9\% reported one or more depressive disorders since baseline, which is four times more than among the 798 respondents without subthreshold depressive disorder at baseline (7.1\%). Of the 466 respondents with a history of depressive disorder, $23.0 \%$ had developed a depressive disorder by the time of the 2-year follow-up, an occurrence three times higher than among the 701 respondents without a history of depressive disorder (7.6\%).

The rates of anxiety disorders are shown in Table 3 and Fig. 2. Of the 227 respondents with baseline subthreshold anxiety, 25.6\% reported one or more anxiety disorders since baseline, an occurrence over three times higher than among the 940 respondents without subthreshold anxiety (7.6\%). Of the 321 respondents with a history of anxiety disorder, $21.2 \%$ developed an anxiety disorder by the time of the 2-year follow-up, almost three times more than
Table 1 Sociodemographic and clinical characteristics at baseline $(n=1167)$

\section{Characteristics}

\begin{tabular}{|lc|}
\hline Gender: male, $n$ (\%) & $399(34.2)$ \\
\hline Subthreshold depression, $n$ (\%) & $369(31.6)$ \\
\hline Subthreshold anxiety, $n(\%)$ & $227(19.5)$ \\
\hline No history of depressive or anxiety disorder, $n$ (\%) & $598(51.2)$ \\
\hline No history of depressive disorder, $n$ (\%) & $701(60.1)$ \\
\hline No history of anxiety disorder, $n$ (\%) & $846(72.5)$ \\
\hline History of major depressive disorder, $n$ (\%) & $458(39.2)$ \\
\hline History of dysthymia, $n$ (\%) & $110(9.4)$ \\
\hline History of social phobia, $n$ (\%) & $124(10.6)$ \\
\hline History of panic disorder, $n$ (\%) & $98(8.4)$ \\
\hline History of agoraphobia, $n$ (\%) & $84(7.2)$ \\
\hline History of generalised anxiety disorder, $n$ (\%) & $130(11.1)$ \\
\hline Age, mean (s.d.) & $42.6(13.9)$ \\
\hline Number of somatic conditions, mean (s.d.) & $1.6(1.3)$ \\
\hline Years of education, mean (s.d.) & $12.8(3.2)$ \\
\hline Inventory of Depressive Symptomatology-Self Report-30 score, \\
mean (s.d.) & $11.1(8.5)$ \\
\hline Beck Anxiety Inventory score, mean (s.d.) & $5.5(5.7)$ \\
\hline a. Some respondents have a history of more than one disorder. \\
\hline
\end{tabular}

among the 846 respondents without a history of anxiety disorder $(7.2 \%)$.

\section{History and subthreshold disorder as predictors of the occurrence of depressive disorders}

Odds ratios (ORs) and 95\% confidence intervals for the occurrence of any depressive disorder in the 2 years following baseline are listed in Table 4. Univariate regression analyses show that the occurrence of any depressive disorder was predicted by the combination of a history of depression and subthreshold depression, a combination of a history of anxiety and subthreshold anxiety, a history of depressive or anxiety disorder alone and subthreshold depression or anxiety alone. Using multiple regression analysis, a history of anxiety and subthreshold anxiety on their own dropped below significance levels, and only the combination of a history of anxiety and subthreshold anxiety at baseline predicted the occurrence of depressive disorder. In contrast, subthreshold depression alone, a history of depressive disorder alone and the combination of the two remained predictors of the occurrence of depressive disorder. Note that the effect of history and subthreshold symptoms combined $(\mathrm{OR}=10.00)$ can be characterised as additive relative to either effect on its own, as the expected value of an additive effect would correspond to

\begin{tabular}{|c|c|c|c|c|}
\hline & $n$ & $\begin{array}{l}\text { Any depressive disorder, } \\
n(\%)\end{array}$ & $\begin{array}{c}\text { Dysthymia, } \\
n(\%)\end{array}$ & $\begin{array}{c}\text { Major depressive } \\
\text { disorder, } n(\%)\end{array}$ \\
\hline No subthreshold depressive disorder at baseline & 798 & $57(7.1)$ & $6(0.8)$ & $55(6.9)$ \\
\hline History of dysthymia & 43 & $10(23.3)$ & $1(2.3)$ & $10(23.3)$ \\
\hline History of major depressive disorder & 245 & $36(14.7)$ & $5(2.0)$ & $34(13.9)$ \\
\hline No history of dysthymia/major depressive disorder & 549 & $21(3.8)$ & $1(0.2)$ & $21(3.8)$ \\
\hline Subthreshold depression at baseline & 369 & $103(27.9)$ & $12(3.3)$ & $102(27.6)$ \\
\hline History of dysthymia & 67 & $28(41.8)$ & $6(9.0)$ & $28(41.8)$ \\
\hline History of major depressive disorder & 213 & 70 (32.9) & $8(3.8)$ & $70(32.9)$ \\
\hline No history of dysthymia/major depressive disorder & 152 & $32(21.1)$ & $4(2.6)$ & $31(20.4)$ \\
\hline Total & 1167 & $160(13.7)$ & $18(1.5)$ & 157 (13.5) \\
\hline
\end{tabular}




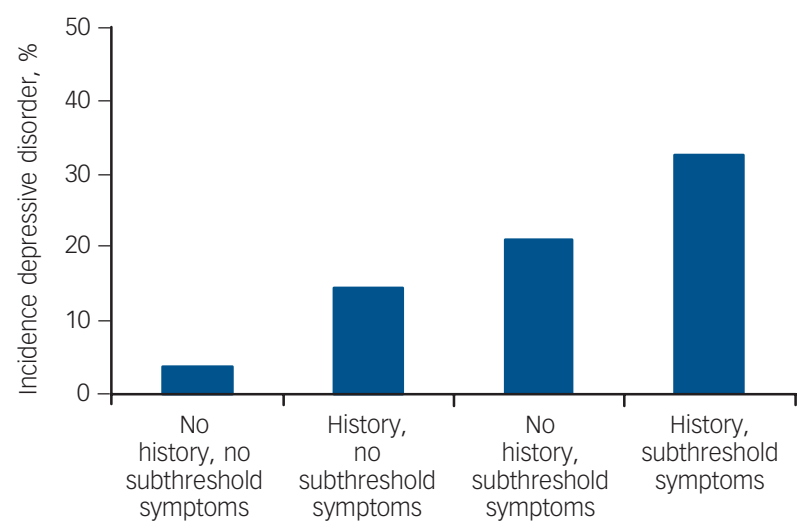

Fig. 1 Occurrence of depressive disorder by history of depressive disorder and subthreshold depression at baseline.

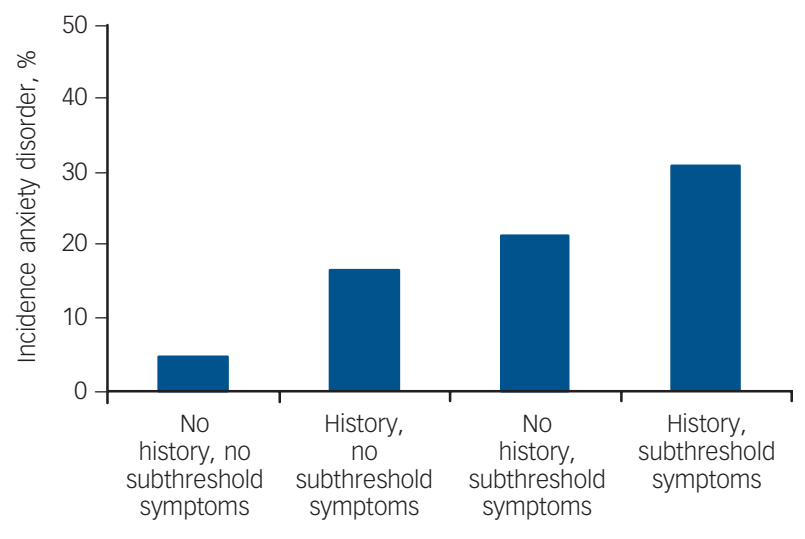

Fig. 2 Occurrence of depressive disorder by history of anxiety disorder and subthreshold anxiety at baseline.

\begin{tabular}{|c|c|c|c|c|c|c|}
\hline & $n$ & $\begin{array}{c}\text { Any anxiety } \\
\text { disorder, } n(\%)\end{array}$ & $\begin{array}{c}\text { Social phobia, } \\
n(\%)\end{array}$ & $\begin{array}{c}\text { Panic disorder, } \\
n(\%)\end{array}$ & $\begin{array}{c}\text { Agoraphobia, } \\
n(\%)\end{array}$ & $\begin{array}{l}\text { General anxiety } \\
\text { disorder, } n(\%)\end{array}$ \\
\hline No subthreshold anxiety disorder at baseline & 940 & $71(7.6)$ & $26(2.8)$ & $19(2.0)$ & $17(1.8)$ & $15(1.6)$ \\
\hline History of social phobia & 91 & $18(19.8)$ & $12(13.2)$ & $6(6.6)$ & $3(3.3)$ & $3(3.3)$ \\
\hline History of panic disorder & 65 & $6(9.2)$ & $2(3.1)$ & $2(3.1)$ & $2(3.1)$ & $1(1.5)$ \\
\hline History of agoraphobia & 54 & $12(22.2)$ & $4(7.4)$ & $3(5.6)$ & $9(16.7)$ & $2(3.7)$ \\
\hline History of GAD & 87 & $15(17.2)$ & $5(5.7)$ & $5(5.7)$ & $4(4.6)$ & $2(2.3)$ \\
\hline No history of anxiety & 719 & $34(4.7)$ & $11(1.5)$ & $9(1.3)$ & $5(0.7)$ & $8(1.1)$ \\
\hline Subthreshold anxiety at baseline & 227 & $58(25.6)$ & $18(7.9)$ & $24(10.6)$ & $12(5.3)$ & $14(6.2)$ \\
\hline History of social phobia & 33 & $9(27.3)$ & $6(18.2)$ & $3(9.1)$ & $2(6.1)$ & $1(3.0)$ \\
\hline History of panic disorder & 33 & $13(39.4)$ & $3(9.1)$ & $6(18.2)$ & $6(18.2)$ & $4(12.1)$ \\
\hline History of agoraphobia & 30 & $11(36.7)$ & $5(16.7)$ & $5(16.7)$ & $4(13.3)$ & $3(10.0)$ \\
\hline History of GAD & 43 & $12(27.9)$ & $3(7.0)$ & $6(14.0)$ & $2(4.7)$ & $2(4.7)$ \\
\hline No history of anxiety & 127 & $27(21.3)$ & $7(5,5)$ & $10(7.9)$ & $4(3.1)$ & $6(4.7)$ \\
\hline Total & 1167 & $129(11.1)$ & $44(3.8)$ & $43(3.7)$ & $29(2.5)$ & $29(2.5)$ \\
\hline
\end{tabular}

\begin{tabular}{|c|c|c|c|c|}
\hline & \multicolumn{2}{|c|}{ Depressive disorder, OR (95\% Cl) } & \multicolumn{2}{|c|}{ Anxiety disorder, OR (95\% Cl) } \\
\hline & Univariate & Multiple regression & Univariate & Multiple regression \\
\hline Gender & $1.13(0.79-1.61)$ & $0.85(0.58-1.25)$ & $1.74(1.14-2.65)^{\star}$ & $1.36(0.87-2.15)$ \\
\hline Age & $0.99(0.98-1.00)$ & $0.98(0.97-0.99)^{*}$ & $1.00(0.99-1.01)$ & $0.99(0.98-1.01)$ \\
\hline Years of education & $0.94(0.90-0.99)^{*}$ & $0.98(0.93-1.04)$ & $0.95(0.89-1.00)$ & $0.99(0.93-1.06)$ \\
\hline Number of somatic illnesses & $1.17(1.04-1.31)^{* *}$ & $1.06(0.93-1.21)$ & $1.11(0.98-1.27)$ & $1.01(0.87-1.17)$ \\
\hline \multicolumn{5}{|l|}{ Depressive disorder } \\
\hline History of depressive disorder & $4.25(2.42-7.45)^{\star \star *}$ & $4.15(2.32-7.44)^{\star * *}$ & $2.81(1.54-5.12)^{\star *}$ & $2.02(1.07-3.79)^{*}$ \\
\hline Subthreshold depression & $6.71(3.74-12.04)^{* * *}$ & $6.23(3.31-11.74)^{* * *}$ & $5.68(3.12-10.33)^{\star * *}$ & $3.47(1.78-6.78)^{* * *}$ \\
\hline $\begin{array}{l}\text { History of depressive disorder } \\
\text { and subthreshold depression }\end{array}$ & $12.23(7.27-20.57)^{* * *}$ & $10.00(5.49-18.20)^{* * *}$ & $8.54(5.01-14.54)^{* * *}$ & $4.07(2.18-7.59)^{* * *}$ \\
\hline \multicolumn{5}{|l|}{ Anxiety disorder } \\
\hline History of anxiety & $2.47(1.60-3.82)^{\star * *}$ & $1.38(.86-2.22)$ & $4.05(2.47-6.64)^{\star \star *}$ & $2.82(1.66-4.79)^{\star * *}$ \\
\hline Subthreshold anxiety & $2.88(1.60-3.82)^{* * *}$ & $1.07(0.60-1.92)$ & $5.44(3.15-9.40)^{* * *}$ & $2.65(1.41-4.99)^{* *}$ \\
\hline History of anxiety and subthreshold anxiety & $6.02(3.69-9.83)^{* \star *}$ & $2.04(1.15-3.61)^{\star}$ & $9.05(5.24-15.63)^{\star * *}$ & $4.17(2.22-7.85)^{* * *}$ \\
\hline
\end{tabular}

the sum of 4.15 and 6.23 minus 1 , which is roughly midway in the confidence interval of the estimated combined effect $5.49-18.20 .^{33,34}$ A higher number of somatic illnesses and fewer years of education also predicted the occurrence of depressive disorder in univariate analyses, but not in the multiple regression analysis. Older age predicted a lower occurrence of depression using multiple regression analysis. For predicting the occurrence of depressive disorder within 2 years, the $c$-statistic of the total model was 0.74 , indicating a reasonable discriminative ability.

Of the 160 individuals who developed a depressive disorder between baseline and 2-year follow-up, 63 also developed a comorbid anxiety disorder. The multiple regression analysis was repeated excluding these 63 individuals. The combination of a history of anxiety disorder and subthreshold anxiety no longer 
predicted the occurrence of depressive disorder, leaving a combination of a history of depression and subthreshold depression $(\mathrm{OR}=11.35,95 \%$ CI 5.41-23.81), subthreshold depression alone $(\mathrm{OR}=7.97,95 \% \mathrm{CI} 3.68-17.24)$ and a history of depression ( $\mathrm{OR}=4.85,95 \%$ CI 2.37-9.94) as predictors for the occurrence of depressive disorder.

\section{History and subthreshold disorder as predictors of the occurrence of anxiety disorders}

Both univariate and multiple regression analyses showed that the occurrence of anxiety disorders was best predicted by a combination of a history of anxiety disorder and subthreshold anxiety, closely followed by a combination of a history of depressive disorder and subthreshold depression (Table 4). Subthreshold anxiety alone, subthreshold depression alone, a history of anxiety disorder alone, and a history of depressive disorder alone all predicted the occurrence of anxiety disorder as well, although a history of depressive disorder dropped below significance in multiple regression analysis. Again, the effect of symptoms history and subthreshold combined can be characterised as additive relative to either effect on its own, as the expected values are within the confidence intervals for anxiety $(2.22-7.85)$ as well as depressive disorder $(2.18-7.59) .{ }^{33,34}$ To a small extent, female gender also predicted the occurrence of anxiety disorder in the univariate analysis, but not in the multiple regression analysis. For predicting the occurrence of anxiety disorder within 2 years, the $c$-statistic of the total model was 0.72 , indicating a reasonable discriminative ability.

Of the 129 individuals who developed anxiety disorder between baseline and 2-year follow-up, 63 developed a comorbid depressive disorder. To determine the predictors specifically for anxiety disorder, the multiple regression analysis was repeated, excluding these 63 individuals. A history of depressive disorder no longer significantly predicted the occurrence of anxiety disorder. Otherwise results remained very similar to the prior analyses with the 63 participants included, i.e. combinations of history and subthreshold symptoms of either disorder, and subthreshold symptoms alone of either disorder predicted the occurrence of anxiety disorder, as did a history of anxiety alone.

\section{Post hoc analyses}

The finding that depression predicted the occurrence of anxiety disorders led us to explore post hoc the predictive value of depression for the individual anxiety disorders of social phobia, panic disorder, agoraphobia and generalised anxiety disorder. Multiple regression analyses indicated that depression predicted the occurrence of social phobia and generalised anxiety disorder, but not panic disorder or agoraphobia. More specifically, social phobia was predicted by subthreshold depression alone $(\mathrm{OR}=3.28$, 95\% CI 1.29-8.3), and by a combination of depressive disorder and subthreshold depression $(\mathrm{OR}=2.98$, 95\% CI 1.23-7.20), whereas generalised anxiety disorder was predicted by a combination of depressive disorder and subthreshold depression $(\mathrm{OR}=14.07,95 \%$ CI 3.67-53.91), followed by a history of depressive disorder alone $(\mathrm{OR}=5.90,95 \% \mathrm{CI}$ 1.54-22.67) and subthreshold depression alone (OR $=6.05,95 \%$ CI 1.37-26.64). It should be noted however, as can be seen in Table 3, that the occurrence rates in this study are rather low for any definite conclusions on the individual anxiety disorders.

\section{Discussion}

\section{Main findings}

In this study, we investigated whether a history of a depressive disorder or anxiety disorder and subthreshold symptoms were predictors for the occurrence of depressive or anxiety disorder over 2 years. Two conclusions follow from our findings. First, both a history and subthreshold symptoms of a given disorder independently predicted the occurrence of the disorder within 2 years, with a combination of the two carrying the highest, additive risk. Second, a history of depressive disorder and subthreshold depression signalled the occurrence of either depressive or anxiety disorder, whereas a history of anxiety disorder or subthreshold anxiety signalled the occurrence of anxiety only.

The finding that depression predicted the occurrence of anxiety disorder, separately from depressive disorder, may be explained by the diverse nature of anxiety disorders. Although some are characterised by explicit fear, others are based on anxious worry. Post hoc exploration indicated that depression predicted generalised anxiety disorder and social phobia (but not panic disorder or agoraphobia). Thus, depression predicted those anxiety disorders that, like depression, emphasise worrying.

Predictors directly related to disorder (history and subthreshold symptoms) were much stronger predictors for the occurrence of a disorder than sociodemographic factors such as gender or level of education. The fact that they did not predict the occurrence of depressive or anxiety disorders, not even in univariate analyses, may be explained by the way participants were recruited. Recruitment in NESDA was based mostly on the presence of (or risk of) depressive or anxiety disorder. Thus, the 2-year occurrence rates consisted more of recurrence than of first occurrence of depressive or anxiety disorder. Although gender and socioeconomic status are known predictors of first occurrence of disorder, they are not for recurrence. ${ }^{35}$

We found that $13.7 \%$ of our sample developed a depressive disorder and $11.1 \%$ an anxiety disorder within 2 years, which is much higher than the 3-year occurrence rates in, for example, the Dutch general population study NEMESIS (4.7\% and 3.7\%, respectively). ${ }^{36}$ Again this finding should be seen in light of recruitment in NESDA. About half the participants in the present sample had a history of psychopathology. When we narrowed our sample down to those without a history of depressive or anxiety disorder $(n=598)$, as in the aforementioned study from NEMESIS, 6.7\% developed a depressive disorder within 2 years, and $5.7 \%$ developed an anxiety disorder within 2 years; which is more in line with NEMESIS findings.

\section{Implications}

The findings of this study have implications for mental healthcare and research. We have shown that only two indicators - history and subthreshold symptoms - have an independent and reasonable discriminative ability (overall $c$-statistic $0.72-0.74$ ) to predict who will suffer from depressive or anxiety disorder within a 2-year period. Being able to predict which individuals are most likely to develop a depressive disorder or an anxiety disorder may aid in directing preventive interventions to those most at risk. Preventive interventions have been shown as an effective strategy in reducing the occurrence of depressive and anxiety disorders, in a variety of settings, ${ }^{6}$ lowering the burden of these high-impact and widespread disorders. In a recent review, Muñoz et al ${ }^{6}$ concluded that at least $22 \%$ and up to $50 \%$ of cases of major depressive disorder could be prevented each year. Studies on risk factors such as this one can improve the effectiveness of preventive intervention by pointing out who is most likely to benefit from the intervention. Future research may further narrow down the population most at risk. For example, Cuijpers et $a l^{37}$ found that a family history of depressive disorder and chronic illnesses predicted the occurrence of major depressive disorder among those with subthreshold depression. 
Outside of the research context, the cooperation of participants in interventions is known to drop. This may be especially true for preventive interventions, when there are no symptoms that are discomforting or impairing. However, it is not a good reason to give up on the prevention of depressive or anxiety disorder. Given the large numbers of people involved and the large impact these disorders have on quality of life and functioning, even if only a relatively small percentage of those eligible are engaged, prevention would yield both considerable and worthwhile gains. Studies that can pinpoint those most at risk can improve adherence rates. Knowing with a degree of certainty that a depressive or anxiety disorder is likely to be a reality in the near future may motivate those at risk. Keeping preventive interventions as non-intrusive as possible may also improve cooperation. Stepped-care models, ranging from (prolonged) monitoring, to self-help programmes, to counsellor-guided programmes and to medication, may decrease the burden of participating and improve adherence.

On a conceptual level, the finding of this study, that a history of an episode of a disorder predicts the occurrence of a subsequent episode, indicates its recurrent nature. The finding that subthreshold disorder predicts the occurrence of a full-blown episode supports the concept of a gradual onset or remission, as opposed to an 'all-or-nothing' occurrence. Our findings are therefore in line with a gradual shift in focus on dimensions of psychopathology, as opposed to categories, in DSM-5. ${ }^{38}$

\section{Strengths and weaknesses}

The present study has both weaknesses and strengths. First, although the total sample was quite large, our focus on occurrence did not allow the exploration of interactions between subthreshold disorder, a history of disorder and sociodemographic factors. Future studies may focus on this, as well as investigating additional tell-tale risk factors for the occurrence of depressive or anxiety disorders. Second, the sample size did not allow differentiation in the occurrence of the different depressive (major depressive disorder and dysthymia) and anxiety disorders (social phobia, panic disorder, agoraphobia and generalised anxiety disorder) or differentiation between different cohorts. A particular strength of this study is the prospective design, which enabled us to go beyond retrospectively collected or cross-sectional associations between risk factor and mental illness.

\section{Summary}

In conclusion, we found that a prior history of a disorder and subthreshold symptoms of this disorder both independently predicted the disorder's occurrence within 2 years with the highest risk for individuals having both. Whereas anxiety (subthreshold, in lifetime or both) predicted the occurrence of an anxiety disorder only, depression (a prior history of, subthreshold or both) predicted the occurrence of both depressive and anxiety (generalised anxiety disorder and social phobia) disorders. The ability to predict to a certain degree which individuals will develop a depressive or anxiety disorder in the near future may provide opportunities for preventive interventions for and monitoring of those most at risk.

\section{Funding}

The infrastructure for the NESDA study (www.nesda.nl) is funded through the Geestkracht programme of the Netherlands Organisation for Health Research and Development (Zon-Mw, grant number 10-000-1002) and is supported by participating universities and mental healthcare organisations: VU University Medical Center, GGZ inGeest, Arkin, Leiden University Medical Center, GGZ Rivierduinen, University Medical Center Groningen, Lentis, GGZ Friesland, GGZ Drenthe, Scientific Institute for Quality of Healthcare (IQ healthcare), GGZ Friesland, GGZ Drenthe, Scientific Institute for Quality of Healthcare (IQ healthcare),
Netherlands Institute for Health Services Research (NIVEL) and Netherlands Institute of Mental Health and Addiction (Trimbos Institute).
Julie Karsten, MSc, Catharina A. Hartman, PhD, University Medical Center Groningen, Department of Psychiatry, University of Groningen, Groningen, The Netherlands; Johannes H. Smit, PhD, VU University Medical Center, Department of Psychiatry/EMGO Institute/Neuroscience Campus Amsterdam, Amsterdam, The Netherlands; Frans G. Zitman, MD, Leiden University Medical Center, Department Netherlands; Frans G. Zitman, MD, Leiden University Medical Center, Department
of Psychiatry, Leiden, The Netherlands; Aartjan T. F. Beekman, MD, VU University Medical Center, Department of Psychiatry/EMGO Institute/Neuroscience Campus Amsterdam, Amsterdam, The Netherlands; Pim Cuijpers, PhD, VU University, Department of Clinical Psychology, Amsterdam, The Netherlands; A. J. Willem van der Does, PhD, Leiden University, Institute of Psychology, Leiden, The Netherlands; Johan Ormel, PhD, Willem A. Nolen, MD, University Medical Center Groningen, Department of Psychiatry, University of Groningen, Groningen, The Netherlands; Brenda W. J. H. Penninx, PhD, VU University Medical Center, Department of Psychiatry/EMGO Institute/Neuroscience Campus Amsterdam, Amsterdam, and University Medical Center Groningen, Department of Psychiatry, University of Groningen, Groningen, and Leiden University Medical Center, Department of Psychiatry, Leiden, The Netherlands

Correspondence: Julie Karsten, University Medical Center Groningen, Department of Psychiatry, PO box 660, 9700 AR, Groningen, The Netherlands. E-mail: J.Karsten@accare.nl

First received 29 Mar 2010, final revision 9 Sep 2010, accepted 3 Nov 2010

\section{References}

1 Kessler RC, Chiu WT, Demler O, Walters EE. Prevalence, severity, and comorbidity of 12-month DSM-IV disorders in the National Comorbidity Survey Replication. Arch Gen Psychiatry 2005; 62: 617-27.

2 Kessler RC, Merikangas KR, Wang PS. Prevalence, comorbidity, and service utilization for mood disorders in the United States at the beginning of the twenty-first century. Annu Rev Clin Psychol 2007; 3: 137-58.

3 Kroenke K, Spitzer RL, Williams JBW, Monahan PO, Löwe B. Anxiety disorders in primary care: prevalence, impairment, comorbidity, and detection. Ann Intern Med 2007; 146: 317-25.

4 Judd LL, Paulus MP, Wells KB, Rapaport MH. Socioeconomic burden of subsyndromal depressive symptoms and major depression in a sample of the general population. Am J Psychiatry 1996; 153: 1411-7.

5 Cuijpers $\mathrm{P}$, Van Straten A, Smit F, Mihalopoulos C, Beekman ATF. Preventing the onset of depressive disorders: a meta-analytic review of psychological interventions. Am J Psychiatry 2008; 165: 1272-80.

6 Muñoz RF, Cuijpers P, Smit F, Barrera AZ, Leykin Y. Prevention of major depression. Annu Rev Clin Psychol 2010; 6: 181-212.

7 Angst J, Gamma A, Sellaro R, Lavori PW, Zhang H. Recurrence of bipolar disorders and major depression: a life-long perspective. Eur Arch Psychiatry Clin Neurosci 2003; 253: 236-40.

8 vuorilehto MS, Melartin TK, Isometsä ET. Course and outcome of depressive disorders in primary care: a prospective 18-month study. Psychol Med 2009; 39: 1697-707.

9 Cuijpers P, Smit F. Subthreshold depression as a risk indicator for major depressive disorder: a systematic review of prospective studies. Acta Psychiatr Scand 2004; 109: 325-31.

10 Merikangas KR, Zhang $H$, Avenevoli S, Acharyya S, Neuenschwander M, Angst J. Longitudinal trajectories of depression and anxiety in a prospective community study. Arch Gen Psychiatry 2003; 60: 993-1000.

11 Batelaan NM, De Graaf R, Spijker J, Smit, JH, Van Balkom JLM, Vollebergh WAM, et al. The course of panic attacks in individuals with panic disorder and subthreshold panic disorder: a population-based study. J Affect Disord 2010; 121: 30-8.

12 Acarturk C, Smit F, De Graaf R, Van Straten A, Ten Have M, Cuijpers P. Incidence of social phobia and identification of its risk indicators: a model for prevention. Acta Psychiatr Scand 2009; 119: 62-70.

13 Penninx BWJH, Beekman AT, Smit JH, Zitman FG, Nolen WA, Spinhoven $\mathrm{P}$ et al. The Netherlands Study of Depression and Anxiety (NESDA): rationale objectives and methods. Int J Methods Psychiatr Res 2008; 17: 121-40.

14 Donker T, Comijs H, Cuijpers P, Terluin B, Nolen W, Zitman F, et al. The validity of the Dutch $\mathrm{K} 10$ and extended K10 screening scales for depressive and anxiety disorders. Psychiatry Res 2010; 176: 45-50.

15 Kessler RC, Andrews G, Mroczek D, Üstün B, Wittchen HU. World Health Organization Composite International Diagnostic Interview short-form (CIDI-SF). Int J Methods Psychiatr Res 1998; 7: 171-85.

16 Kessler RC, Andrews G, Colpe LJ, Hiripi E, Mroczek DK, Normand S-LT, et al. Short screening scales to monitor population prevalences and trends in non-specific psychological distress. Psychol Med 2002; 32: 959-76.

17 Ansseau M, Fischler B, Dierick M, Albert A, Leyman S, Mignon A. Socioeconomic correlates of generalized anxiety disorder and major depression in primary care: the GADIS II study (Generalized Anxiety and Depression Impact Survey II). Depress Anxiety 2008; 25: 506-13. 
18 Bijl RV, Ravelli A. Current and residual functional disability associated with psychopathology: findings from the Netherlands Mental Health Survey and Incidence Study. Psychol Med 2000; 30: 657-68.

19 Beekman ATF, Penninx BWJH, Deeg DJH, Ormel J, Braam AW, Van Tilburg W. Depression and physical health in later life: results from the Longitudinal Aging Study Amsterdam (LASA). J Affect Disord 1997; 46: 219-31.

20 World Health Organization. Composite International Diagnostic Interview (CIDI). World Health Organization, 1997.

21 Rush AJ, Giles DE, Schlesser MA, Fulton CL, Weissenburger J, Burns C. The Inventory for Depressive Symptomatology (IDS): preliminary findings. Psychiatry Res 1986; 18: 65-87.

22 Rush AJ, First MB, Burns B. Handbook of Psychiatric Measures (2nd edn). American Psychiatric Publishing, 2008.

23 Corruble E, Legrand JM, Duret C, Charles G, Guelfi JD. IDS-C and IDS-SR: psychometric properties in depressed in-patients. J Affect Disord 1999; 56 95-101.

24 Rush AJ, Trivedi MH, Carmody TJ, Ibrahim HM, Markowitz JC, Keitner GI, et al. Sef-reported depressive symptom measures: sensitivity to detecting change in a randomized, controlled trial of chronically depressed, nonpsychotic outpatients. Neuropsychopharmacol 2005; 30: 405-16.

25 Trivedi MH, Rush AJ, Ibrahim HM, Carmody TJ, Biggs MM, Suppes T, et al. The Inventory of Depressive Symptomatology, Clinician Rating (IDS-C) and Self-Report (IDS-SR) and the Quick Inventory of Depressive Symptomatology, Clinician Rating (QIDS-C) and Self-Report (QIDS-SR) in public sector patients with mood disorders: a psychometric evaluation. Psychol Med 2004; 34: 73-82.

26 Karsten J, Hartman CA, Ormel J, Nolen WA, Penninx BWJH. Subthreshold depression based on functional impairment better defined by symptom severity than by number of DSM-IV symptoms. J Affect Disord 2010; 123 230-7.

27 Beck AT, Epstein N, Brown G, Steer RA. An inventory for measuring clinica anxiety: psychometric properties. J Consult Clin Psychol 1988; 56: 893-7.
28 Steer RA, Ranieri WF, Beck AT, Clark DA. Further evidence for the validity of the Beck Anxiety Inventory with psychiatric outpatients. J Anxiety Disord 1993; 7: 195-205.

29 Beck AT, Steer RA. Relationship between the Beck Anxiety Inventory and the Hamilton Anxiety Rating Scale with anxious outpatients. J Anxiety Disord 1991; 5: 213-23.

30 Borden JW, Peterson DR, Jackson EA. The Beck Anxiety Inventory in nonclinical samples: initial psychometric properties. J Psychopathol Behav 1991; 4: 345-56.

31 Karsten J, Nolen WA, Penninx BWJH, Hartman CA. Subthreshold anxiety better defined by Beck Anxiety Inventory than the Composite International Diagnostic Interview. J Affect Disord 2010; Oct 16 (Epub ahead of print).

32 Hosmer DW, Lemeshow S. Applied Logistic Regression. Wiley, 2000.

33 Darroch J. Biologic synergism and parallelism. Am J Epidemiol 1997; 145 661-8.

34 Ormel J, Oldehinkel AJ, Brilman El. The interplay and etiological continuity of neuroticism, difficulties, and life events in the etiology of major and subsyndromal, first and recurrent depressive episodes in later life. Am J Psychiatry 2001; 158: 885-91.

35 Burcusa SL, Iacono WG. Risk for recurrence in depression. Clin Psychol Rev 2007: 27: 959-85.

36 De Graaf R, Bijl RV, Ten Have M, Beekman ARF, Vollebergh WAM. Rapid onset of comorbidity of common mental disorders: findings from the Netherlands Mental Health Survey and Incidence Study (NEMESIS). Acta Psychiatr Scand 2004; 109: 55-63.

37 Cuijpers $P$, Smit F, Willemse G. Predicting the onset of major depression in subjects with subthreshold depression in primary care: a prospective study Acta Psychiatr Scand 2005; 111: 133-8.

38 Andrews G, Anderson TM, Slade $\mathrm{T}$, Sunderland M. Classification of anxiety and depressive disorders: problems and solutions. Depress Anxiety 2008; 25 274-81.

\section{psychiatry in the Old Testament}

\section{The case of King Saul: did he have recurrent unipolar depression or bipolar affective disorder?}

\section{George Stein}

It is widely accepted that Saul, the first king of Israel, had a mental disorder. Probably it was depression, soothed when David played on his harp: 'And whenever the evil spirit from God came upon Saul, David took the lyre and played it in his hand, and Saul would be relieved and feel better and the evil spirit would depart from him (1 Sam. 16:23).'

Rather less well known are two passages that suggest he may have suffered from mania as well. Thus, shortly after being anointed king by the prophet Samuel but before he assumed the throne, saul gets lost in the woods while searching for some lost donkeys, and there he meets a band of prophets.

10:10 'When they were going from there to Gibeah a band of prophets met him and the spirit of God possessed him and he fell into a prophetic frenzy along with them. 11 When all who knew him before saw how he prophesied with the prophets the people said to one another "What has come over the son of Kish? Is Saul also among the prophets?" 12 A man of the place answered "And who is their father?" Therefore it became a proverb "Is Saul among the prophets?" 13 When his prophetic frenzy had ended he went home.

This passage describes a brief episode where Saul behaved out of character and was in a state of prophetic frenzy similar to that of the prophets (many of whom were accepted as being mad and subject to prophetic ecstasy). The second episode of possible mania occurs towards the end of Saul's reign when, in a jealous rage, he and his army are pursuing David across the desert and they have heard David is in a place called Naioth.

19:23 'He went then towards Naioth in Ramah; and the spirit of God came upon him. As he was going he fell into a prophetic frenzy until he came to Naioth in Ramah. 24 He too stripped off his clothes and he too fell into a frenzy before Samuel. He lay naked all that day and all that night. Therefore it is said, is Saul also among the prophets?'

Both episodes of mania may have occurred in the presence of others who also went into states of excitement suggesting epidemic hysteria. Thus, in the first episode it is the prophets Saul encounters and in the second episode all his soldiers fell into a state of prophetic frenzy. Saul strips off his clothes, which sometimes occurs in mania and the pattern in the second episode is similar to the first episode, with the people commenting on his change of character as he briefly behaves like a prophet. Towards the end of his life, Saul descends into a state of paranoia, which culminates in death by suicide following defeat by the Philistines. This may indicate that Saul's condition was more serious than depression. If the above two brief excerpts are accepted as signifying manic episodes, then perhaps Saul qualifies for a DSM-IV diagnosis of bipolar affective disorder. 